\title{
Lendo o mundo nas aulas de educação física no ensino médio: por uma ecologia de saberes contra-hegemônicos sobre as práticas corporais e o corpo
}

\author{
Reading the world in physical education classes in high school: For an ecology of counter-hegemonic \\ knowledge about body practices and the body
}

Daniel Teixeira Maldonado ${ }^{1}$, Uirá de Siqueira Farias², Valdilene Aline Nogueira ${ }^{2}$

${ }^{1}$ Instituto Federal de Educação, Ciência e Tecnologia de São Paulo (IFSP), São Paulo, Brasil

2 Universidade São Judas (USJT), São Paulo, Brasil

\section{HISTÓRICO DO ARTIGO}

Recebido: 23 março 2021

Revisado: 25 maio 2021

Aprovado: 31 maio 2021

\section{PALAVRAS-CHAVE:}

Educação Física; Ensino Médio; Leitura de Mundo; Ecologia de Saberes.

\section{KEYWORDS:}

Physical Education; High School; World Reading; Knowledge Ecology.

\section{RESUMO}

OBJETIVO: Relatar uma experiência político-pedagógica que ampliou a leitura de mundo dos estudantes do Ensino Médio sobre os conhecimentos contra-hegemônicos produzidos sobre as práticas corporais e o corpo durante as aulas de Educação Física.

MÉTODOS: Foi relatada uma experiência educativa com estudantes do 1ㅇano do curso de Eletrônica integrado ao Ensino Médio do Instituto Federal de São Paulo - Campus SP, entre os meses de agosto e dezembro de 2020. A turma possui aproximadamente 40 alunos e o currículo é constituído por duas aulas semanais de Educação Física.

RESULTADOS: Os estudantes realizaram uma leitura crítica do mundo sobre os saberes contra-hegemônicos sociais, políticos, econômicos, históricos, biológicos e fisiológicos que se relacionam com as práticas corporais e o corpo, produzidos pela literatura científica e movimentos sociais, durante as aulas do componente curricular. CONCLUSÃO: Ao fazer um diálogo entre os conceitos de leitura de mundo e ecologia de saberes contrahegemônicos, produzidos por Paulo Freire e Boaventura de Sousa Santos, passamos a defender que a função social das aulas de educação física está relacionada com a leitura crítica do mundo dos saberes produzidos sobre as danças, lutas, esportes, ginásticas, jogos, brincadeiras e a relação da sociedade com o corpo, pelos grupos que foram marginalizados no sistema capitalista.

\section{ABSTRACT}

OBJECTIVE: To report a political-pedagogical experience that expanded the reading of the world of high school students about the counter-hegemonic knowledge produced about body and body practices during physical education classes.

METHODS: An educational experience was reported with students from the 1st year of the electronics course integrated with high school at the Federal Institute of São Paulo - Campus SP, between the months of august and december of the year 2020. the class has approximately 40 students and the curriculum is consisting of two weekly physical education.

RESULTS: The students carried out a critical reading of the world about the social, political, economic, historical, biological and physiological counter-hegemonic knowledge that is related to body and body practices, produced by scientific literature and social movements, during the classes of the curricular component.

CONCLUSION: By making a dialogue between the concepts of world reading and the ecology of counterhegemonic knowledge, produced by Paulo Freire and Boaventura de Sousa Santos, we come to defend that the social function of Physical Education classes is related to the critical reading of the world of knowledge produced on dances, fights, sports, gymnastics, games and the relationship of society with the body, by groups that were marginalized in the capitalist system. 


\section{INTRODUÇÃO}

As teorias curriculares são formuladas por pesquisadores e professores que buscam organizar uma proposta educativa para alcançar um determinado modelo de ser humano e sociedade. Elas possuem aspectos ontológicos e epistemológicos rígidos, pois a coerência discursiva é de suma importância para a construção de princípios didáticos que dialoguem com a formação de um determinado sujeito.

$\mathrm{Na}$ área de Educação Física, dentre as diversas propostas curriculares produzidas, aquelas que possuem como essência a problematização da realidade na perspectiva de politização dos estudantes sobre os conhecimentos historicamente produzidos relacionados com as práticas corporais e o corpo foram a crítico-superadora (SOARES et al., 1992), a crítico-emancipatória (KUNZ, 2006) e a cultural (NEIRA; NUNES, 2008; NEIRA, 2018).

A materialização das teorias pedagógicas da Educação Física a partir dessas perspectivas epistemológicas fundamentou as aulas do componente curricular na área de Linguagens, a busca por uma sociedade democrática e a legitimação da disciplina com conhecimentos necessários para a formação de um sujeito que realiza a leitura de mundo crítica sobre as práticas corporais e o corpo, desvelando as desigualdades e opressões sociais de classe, raça, gênero e religião, na utopia de construir uma sociedade plural, diversa e equitativa.

Nesse contexto, os professores e as professoras do componente curricular passaram a organizar debates e reflexões com os estudantes sobre uma ecologia de saberes contra-hegemônicos relacionados com as manifestações da cultura corporal (lutas, danças, ginásticas, esportes, jogos e brincadeiras), visando a superação de uma realidade socioeconômica desigual da sociedade brasileira e a formação do pensamento crítico desses alunos e alunas sobre os aspectos sociais, econômicos, políticos, históricos, biológicos e fisiológicos que materializam essas práticas corporais e a relação dos discentes com os seus corpos, ampliando a sua leitura de mundo (MALDONADO, 2020).

Paulo Freire nos faz refletir que ler não se limita a leitura da palavra, o ser humano lê antes o mundo pela sua experiência existencial, é o saber da experiência feito. Ler o mundo antes mesmo de ler a palavra, significa conhecer uma multiplicidade de saberes, desde a distinção dos sons dos pássaros, das cores da natureza, dos diferentes ritmos musicais, das diversas formas de brincar, as diferentes danças, das diferentes formas de vestimenta, os saberes do cultivo das plantas, a ciência de culinária, a capacidade de produzir ferramentas, poemas, histórias e tantos outros saberes, todos sem mesmo saber ainda codificar a palavra escrita, mas que já codifica a palavra falada e o gesto expresso (FREIRE, 2011a).

Ou seja, a leitura de mundo é enxarcada de uma ecologia de saberes sensitiva, esses interpretados constantemente pelos seres humanos, pelo complexo senso de interpretar. Nesse enredo, a cultura é o principal elemento de amalgama entre sujeito, história e contexto, ou seja, nessa dialética que leva a práxis verdadeira (FREIRE, 2011b), pois é entendendo a cultura enquanto ação educativa, resultado de uma dinamicidade do saber experiencial somado à capacidade de ler a palavra escrita, mas numa leitura politizada da palavra, desvelando seus significados, que o ser humano avança para ler o mundo criticamente (FREIRE, 2015a).
Também é preciso reconhecer que a educação é um ato político e a leitura de mundo enquanto uma verdadeira práxis, caso contrário a ação educativa recai na direção de uma prática ingênua ou astuta. Dessa forma, é possível que a leitura de mundo seja orientada pelos saberes da experiência feito, fundamentada numa cultura contextual, que se amplia ao ler a palavra criticamente, alcançado o verdadeiro aprendizado, em que educador e educando, dialogicamente, se reconhecem sujeitos do processo, da criação e da transformação do mundo (FREIRE, 2015a). Assim, ao ler as várias práticas corporais, a humanidade necessita fazê-lo por um binóculo crítico, superando a visão ingênua ou astutamente construída em forma de invasão cultural (2015a).

Na perspectiva de Bossle (2020), em diálogo com os escritos de Paulo Freire, a leitura de mundo acontece com uma análise poderosa da realidade, onde as pessoas aprendem e se reposicionam em um processo gnosiológico orientado pelo diálogo, promovendo conscientização e transformação das classes populares.

Portanto, o objetivo desse estudo foi relatar uma experiência político-pedagógica que ampliou a leitura de mundo dos estudantes do Ensino Médio sobre os conhecimentos contra-hegemônicos produzidos sobre as práticas corporais e o corpo durante as aulas de educação física.

\section{MÉTODOS}

\section{Experiência político-pedagógica}

Esse projeto educativo foi realizado com os estudantes do 10 ano do curso de Eletrônica integrado ao Ensino Médio do Instituto Federal de São Paulo - campus SP, durante o ano letivo de 2020, no âmbito do ensino remoto emergencial ocasionado pela pandemia do coronavírus.

A turma possui aproximadamente 40 estudantes e o currículo é constituído por duas aulas semanais de Educação Física que acontecem no mesmo dia. Antes de iniciar o relato de experiência relacionado com a exposição virtual sobre as práticas corporais e o corpo, que foi realizado entre os meses de agosto e dezembro de 2020, os estudantes participaram de atividades de ensino durante três meses em que eles e elas analisaram crônicas, charges, poemas, poesias, músicas, vídeos, podcasts, artigos científicos e textos jornalísticos que versavam sobre as danças, lutas, ginásticas, esportes, jogos, brincadeiras e as relações de opressão que as juventudes passam constantemente com o seu corpo, por conta da busca incessante por um padrão de beleza inalcançável.

Após esse processo, decidimos em conjunto que os discentes iriam produzir conhecimentos contra-hegemônicos sobre os temas estudados nas aulas do componente curricular, na perspectiva de circular uma ecologia de saberes históricos, sociais, políticos, econômicos, biológicos e fisiológicos sobre as danças, lutas, ginásticas, esportes, jogos e brincadeiras e a relação da sociedade com os corpos dos sujeitos.

Dessa forma, organizamos uma exposição virtual em uma rede social com todos os projetos desenvolvidos pelos jovens durante as aulas de educação física. Em diálogo com o relato da experiência, iremos problematizar como os estudantes passaram a ler o mundo sobre os temas estudados, na perspectiva do 
posicionamento crítico contra toda e qualquer forma de opressão que ocorre sistematicamente contra os grupos que resistem aos ditames do sistema neoliberal.

\section{RESULTADOS E DISCUSSÃO}

\section{Exposição virtual - leitura de mundo sobre as práticas corporais}

Na perspectiva de materializar a ideia de produzir uma exposição virtual nas redes sociais que fizesse circular saberes contra-hegemônicos sobre as práticas corporais e o corpo, reunimos os estudantes em uma aula virtual e apresentamos a proposta. Todos e todas ficaram empolgados com o projeto, mas ao mesmo tempo surgiu a preocupação de onde eles e elas iriam achar referências para pesquisar sobre esses assuntos. Nesse momento, mergulhamos em sites e jornais que produzem reportagens alternativas, que fogem do padrão editorial convencional no território brasileiro, tais como a Revista Carta Capital ${ }^{1}$, o Jornal El País ${ }^{2}$, o Portal Geledés ${ }^{3}$, o Blog Dibradoras ${ }^{4}$ e o site Territórios do Brincar ${ }^{5}$.

Nesses espaços, encontramos diversos artigos que versavam sobre temas relacionados com os marcadores sociais de raça, gênero, classe social, religião, saúde e geração que atravessam as danças, lutas, ginásticas, esportes, jogos e brincadeiras, além de problematizar a relação das pessoas com seu corpo. A seguir, o leitor e a leitora poderão analisar todos os textos que foram disponibilizados aos discentes para que eles e elas elaborassem a sua exposição virtual.

Quadro 1. Artigos utilizados para a elaboração da exposição virtual.

\begin{tabular}{|c|c|}
\hline Título da Reportagem & $\begin{array}{l}\text { Espaço de } \\
\text { Consulta }\end{array}$ \\
\hline Aos seis anos ela ganhou um skate. Aos 12 , é uma das melhores do mundo & El País \\
\hline Roda de capoeira torna-se Patrimônio Cultural Imaterial da Humanidade & Geledés \\
\hline Hoje na História, nascia Jesse Owens, o homem que venceu o racismo & Geledés \\
\hline Do samba ao funk: a voz dos excluídos & Geledés \\
\hline Contra a gordofobia, movimento "corpo livre" ganha força na internet & Carta Capital \\
\hline Brincadeiras tradicionais do Brasil: um salve à cultura da infância & $\begin{array}{l}\text { Território do } \\
\text { Brincar }\end{array}$ \\
\hline A seleção que 'presenteou' a ditadura com uma taça & El País \\
\hline As mulheres negras no esporte brasileiro & Geledés \\
\hline Muhammad Ali, o braço negro contra o racismo & Geledés \\
\hline $\begin{array}{l}\text { Liga das Canelas Pretas, o torneio antirracista nos primórdios do futebol } \\
\text { gaúcho }\end{array}$ & El País \\
\hline Julle, o menino rejeitado no futebol por ser transexual & El País \\
\hline A Bailarina do Tênis & SESC \\
\hline Google resgata história das mulheres proibidas de jogar futebol no Brasil & Dibradoras \\
\hline Jessamyn Stanley: uma "yoga girl" além dos padrões & A Naturalissima \\
\hline
\end{tabular}

Fonte: Elaborado pelos autores.

Dessa forma, organizamos a turma em 16 grupos e entregamos esses materiais para eles. Fizemos um grupo de WhatsApp para cada trabalho e passamos a fazer um diálogo com

\footnotetext{
${ }^{1}$ Disponivel em: https://www.cartacapital.com.br/

${ }^{2}$ Disponivel em: https://brasil.elpais.com/

${ }^{3}$ Disponivel em: https://www.geledes.org.br/

${ }^{4}$ Disponivel em: https://dibradoras.blogosfera.uol.com.br/

${ }^{5}$ Disponivel em: https://territoriodobrincar.com.br/
}

os/as jovens. Enquanto elas e eles faziam a leitura do material e tiravam dúvidas, nós pesquisávamos outros documentos que poderiam ser utilizados na exposição virtual. Assim, após um mês de investigações e reflexões sobre esses temas, os estudantes finalizaram os seus projetos e iniciamos a circulação desses saberes por meio de uma rede social. Criamos uma página no Instagram intitulada "Práticas Corporais e Educação Intercultural" e marcamos as datas para cada temática da exposição. Os temas que os discentes apresentaram podem ser visualizados no quadro a seguir.

Quadro 2. Temas da exposição virtual "Leitura de mundo sobre as práticas corporais".

\begin{tabular}{|cc|}
\hline Práticas corporais e a juventude da periferia & Padrão de Beleza \\
\hline As mulheres no tênis & Capoeira \\
\hline Jogos Mundiais dos povos indígenas & Muhammad Ali \\
\hline Brincadeiras tradicionais & Mulheres negras no esporte \\
\hline Cenário feminino no e-sports & A ditadura e o futebol \\
\hline Gordofobia & Panteras Negras no esporte \\
\hline $\begin{array}{c}\text { Diferenças salarias entre homens e mulheres } \\
\text { nos esportes }\end{array}$ & Racismo no esporte \\
\hline Liga das canelas pretas & Transexuais no esporte \\
\hline
\end{tabular}

Fonte: Elaborado pelos autores

Durante o processo da exposição virtual no Instagram, diversificados conhecimentos contra-hegemônicos produzidos pela humanidade sobre as práticas corporais e o corpo circularam entre os estudantes e seguidores da página. Nesse contexto, problematizamos sobre a história do funk, o movimento de resistência dos capoeiristas para a valorização da cultura negra, a importância do boxeador Muhammad Ali para as conquistas do movimento negro, a proibição do futebol feminino no Brasil e toda a luta das mulheres para conseguir valorização nos esportes, a racismo que ainda persiste em aparecer contra os atletas nos campos, quadras e pistas, as diferenças salariais entre homens e mulheres em diferentes práticas corporais, as evidências científicas que possibilitam a participação de pessoas transexuais nas práticas esportivas de alto nível de acordo com a sua identidade de gênero, a importância dos jogos e das brincadeiras para a valorização da cultura africana e indígena no Brasil, o reconhecimento das práticas corporais indígenas no vasto território nacional, a participação das mulheres nos jogos eletrônicos (E-Sports), a relação tênue entre a ditadura militar no Brasil e o futebol, destacando o movimento de resistência dos atletas que levantaram as suas vozes para lutar pela liberdade de expressão e uma ampla reflexão sobre o padrão de beleza estabelecido pela sociedade contemporânea, valorizando, em contraponto, a boniteza de diversos corpos, da forma que eles são.

Após cada postagem realizada, os estudantes que organizaram o tema dialogavam com os comentários e as perguntas feitas no Instagram pelos colegas de turma, pelo professor e outras pessoas que interagiram na página. Muitos jovens de outras escolas participaram desse debate com perguntas críticas e comentários positivos.

Em diálogo com Sousa Santos (2020), a nossa intencionalidade político-pedagógica com essa experiência foi "decretar" o fim do império cognitivo dos conhecimentos produzidos sobre as práticas corporais e o corpo. Para isso, colocamos em evidên- 
cia os saberes de diversos movimentos sociais sobre as danças, lutas, ginásticas, esportes, jogos, brincadeiras e da relação dos jovens com o seu corpo, fazendo circular a produção intelectual da humanidade que ainda faz resistência ao processo de manutenção das desigualdades e opressões produzidas pelo sistema neoliberal.

Assim, a partir dos estudos de Freire (2011a; 2015a; 2015b; 2016), defendemos que esses conhecimentos de resistência produzidos sobre as manifestações da cultura corporal, que são colocados em evidência por diferentes grupos para combater as injustiças sociais causadas pelo sistema capitalista, ampliam a leitura de mundo dos estudantes sobre essas temáticas, possibilitando a formação do pensamento crítico e a conscientização dos jovens, para que eles e elas possam ser mais.

Com essa perspectiva, fizemos mais uma proposta aos discentes. Em um diálogo realizado na aula remota após a apresentação de todos esses projetos, que aconteceu entre os meses de setembro e outubro, perguntamos aos jovens se eles e elas topavam fazer uma análise mais profunda dos trabalhos produzidos pelos seus colegas, na perspectiva de aprofundar o seu entendimento sobre os temas que estavam sendo problematizados. Após um tempo de conversa, decidimos então realizar uma nova exposição virtual, a partir da releitura dos estudantes relacionadas com os saberes contra-hegemônicos sobre as manifestações da cultura corporal e o corpo que eles estavam acessando nessa experiência.

\section{Exposição virtual - práticas corporais: a luta pela liberdade de expressão se faz na escola}

Ao analisar os trabalhos que os jovens produziram nas suas releituras durante os meses de novembro e dezembro, nos marcou muito a potência da juventude na luta pela liberdade de expressão, dos corpos, dos gêneros, das etnias, das culturas. Todos e todas produziram novos saberes para combater todas as formas de opressão nas relações de poder que são estabelecidos nas vivências das danças, lutas, ginásticas, esportes, jogos e brincadeiras e na forma que as pessoas lidam com seus corpos. Nesse quadro, é possível observar os temas dos novos projetos desenvolvidos pelos discentes que versavam sobre as práticas corporais e o corpo.

Quadro 3. Temas da exposição virtual "Práticas corporais: a luta pela liberdade de expressão se faz na escola"

\begin{tabular}{|c|c|}
\hline Liberdade de expressão & $\begin{array}{l}\text { A política no esporte e a desigualdade de } \\
\text { gênero }\end{array}$ \\
\hline Mulher, negra, tenista e quebrando padrões & Nas margens do sistema \\
\hline As mulheres na capoeira & $\begin{array}{l}\text { Histórias de mulheres inspiradoras nas práticas } \\
\text { corporais e na vida cotidiana }\end{array}$ \\
\hline Discriminação no Esporte & Práticas corporais e brincadeiras indígenas \\
\hline Quebrando Tabu & $\begin{array}{c}\text { A capoeira como forma de resistência cultural } \\
\text { das crianças que residem nas periferias } \\
\text { brasileiras }\end{array}$ \\
\hline $\begin{array}{l}\text { Racismo e a representatividade feminina no } \\
\text { esporte }\end{array}$ & $\begin{array}{l}\text { A inspiração do movimento panteras negras } \\
\text { nas práticas corporais: pela liberdade de } \\
\text { expressão e contra a opressão dos negros no } \\
\text { esporte e na sociedade }\end{array}$ \\
\hline $\begin{array}{l}\text { O padrão de beleza imposto pela sociedade } \\
\text { no esporte }\end{array}$ & O preconceito nos esportes \\
\hline
\end{tabular}

Fonte: Elaborado pelos autores.

A partir da produção de imagens, poesias, slam e vídeos, os jovens contaram belas histórias, de muita resistência, sobre a participação feminina, de pessoas negras, transexuais, indígenas, com deficiência e diferentes corpos nas práticas corporais.

Na Figura 1 será possível apreciar alguns dos praticantes de diversificadas manifestações da cultura corporal que foram mencionados nessa exposição virtual, destacando o movimento de luta que eles e elas realizam diariamente para combater as diversas formas de opressão que atravessam a sociedade.

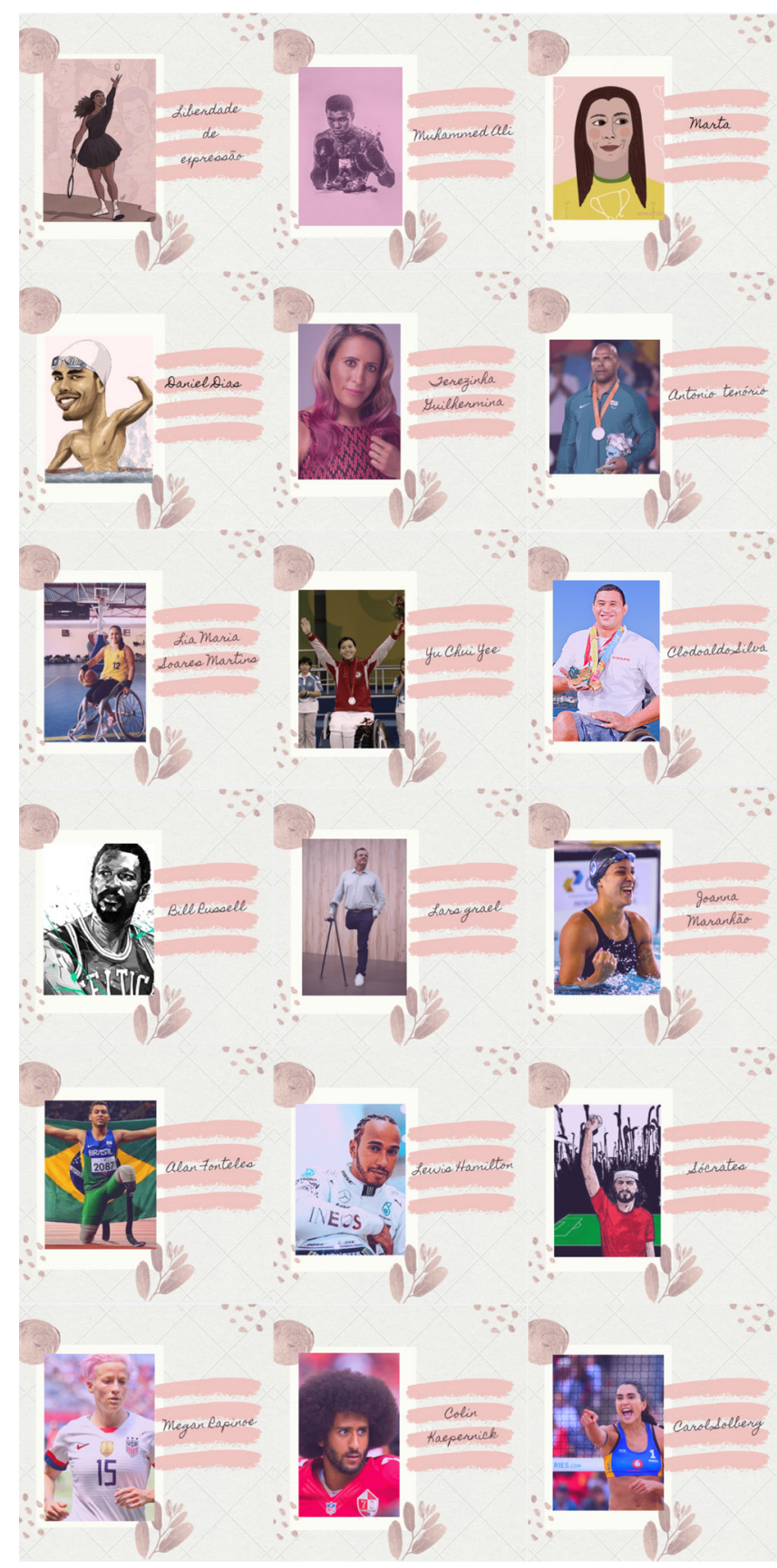

Figura 1. Praticantes de diversificadas manifestações da cultura corporal mencionados na exposição virtual.

Sem sombra de dúvidas, ao compreender a história de cada um desses atletas que foram mencionados na segunda exposição virtual, os jovens conseguiram ter acesso ao movimento de resistência que as mulheres, os negros, as pessoas com menor poder aquisitivo, os indivíduos com deficiências e outros grupos 
marginalizados na sociedade que são praticantes de danças, ginásticas, esportes, lutas, jogos e brincadeiras fazem cotidianamente nos seus espaços.

O slam produzido por um dos grupos destacou, de forma brilhante, a relação de opressão que muitos jovens ainda vivem com os seus corpos, pedindo uma basta para essa realidade, na utopia de construir um muro sem grades, onde todos e todas possam potencializar a vida a partir do seu próprio "padrão de beleza" (Figura 2).

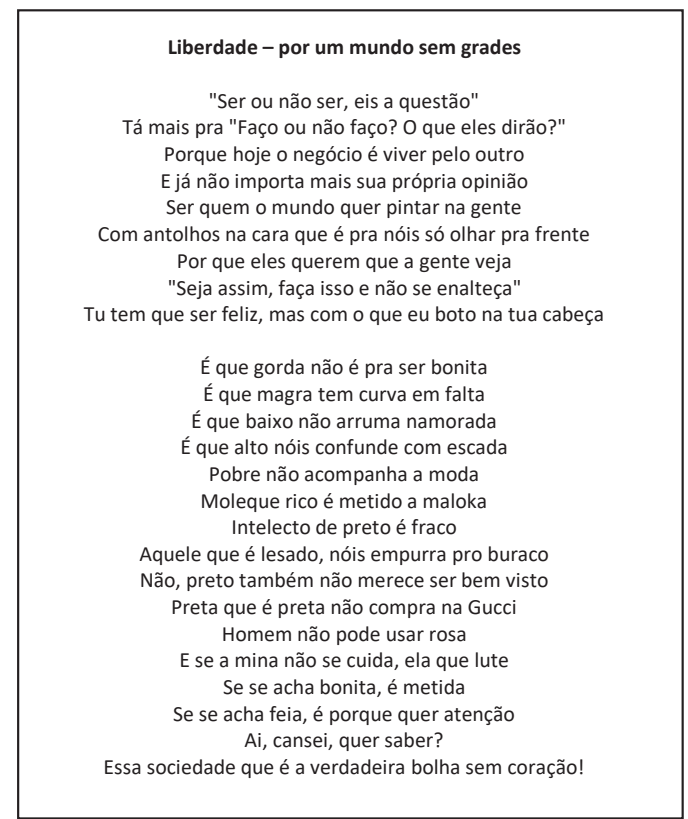

Figura 2. Slam produzido para a exposição virtual "Práticas corporais: a luta pela liberdade de expressão se faz na escola". Fonte: Elaborado pelos estudantes.

As reflexões realizadas nessa segunda exposição também aconteceram pelos comentários na rede social. Todavia, após a finalização dessa exposição, docente e educandos se reuniram em uma aula síncrona realizada no Google Meet para problematizar os conhecimentos que foram analisados, ressignificados e produzidos durante o processo educativo.

Em diálogo com Maldonado, Farias e Nogueira (2021) e com as produções organizadas pelos estudantes do Ensino Médio, defendemos que a leitura de mundo sobre as práticas corporais e o corpo, ancorada na ecologia de saberes contra-hegemônicos sobre esses temas, acontece nas aulas de educação física quando as/os jovens apreciam uma poesia, analisam um texto, admiram uma obra de arte, escutam atenciosamente uma música, vivenciam os gestos das manifestações da cultura corporal, debatem sobre artigos científicos e organizam exposições virtuais nas redes sociais contando histórias de grupos oprimidos que são praticantes das danças, lutas, ginásticas, esportes, jogos e brincadeiras ou sofrem por conta da modelação dos seus corpos.

Assim, a função social das aulas do componente curricular na Educação Básica se efetiva como a possibilidade de os jovens realizarem a leitura de mundo acerca dos saberes históricos, sociais, políticos, econômicos, biológicos e fisiológicos produzidos historicamente pela humanidade sobre as práticas corporais e o corpo, na perspectiva que eles e elas possam ser mais, tornando-se pessoas que defendam um mundo plural, com menos desigualdades socioeconômicas e mais direitos para os grupos oprimidos.

\section{Ler 0 mundo nas aulas de educação física}

Ler o mundo na perspectiva freireana significa se conscientizar sobre os movimentos históricos de opressão que os grupos marginalizados na sociedade passaram durante o seu processo histórico. Ao acessar esse conhecimento, todos e todas, educadores e educandos, em diálogo franco e aberto, passam a entender a realidade em que vivem, se distanciando do discurso fatalista das elites dirigentes (econômicas, raciais, étnicas, religiosas, de gênero) sobre o mundo (FREIRE, 2015a).

Nogueira et al. (2020) mencionam que as aulas de educação física precisam potencializar essa leitura de mundo dos estudantes a partir da tematização de diferentes práticas corporais, da problematização dos conhecimentos históricos, sociais, políticos, econômicos, biológicos e fisiológicos das danças, lutas, ginásticas, esportes, jogos, brincadeiras e da ralação dos jovens com o seu corpo e, por consequência, da conscientização desses estudantes sobre essas temáticas, na perspectiva de que eles e elas possam compreender a luta dos grupos oprimidos na nossa sociedade por seus direitos.

Todavia, para que educadores e educandos possam ser mais, lendo o mundo a partir das lentes de quem sofre diversas opressões, eles e elas necessitam conhecer essa realidade a partir dos saberes produzidos pela humanidade. E esse se torna um grande problema, pois esses conhecimentos, na maioria das vezes, não são colocados em evidência pela mídia tradicional e pela literatura científica hegemônica. Assim, para que esse projeto educativo possa se materializar, concordamos com a ideia de Sousa Santos (2010), de que é preciso romper com o pensamento abissal, que separa os modos de vida que interessam à manutenção do sistema capitalista, daqueles que fazem resistência ao referido modelo social e econômico.

Dessa forma, para possibilitar que os estudantes ampliem a sua leitura de mundo sobre os conhecimentos historicamente produzidos sobre as práticas corporais e o corpo, defendemos que os professores e as professoras de Educação Física precisam organizar as suas aulas selecionando uma ecologia de saberes contra-hegemômicos sobre esses temas, viabilizando o desvelamento da realidade (SOUSA SANTOS, 2018).

Sousa Santos (2018) aponta ainda que o objetivo da ecologia dos saberes é criar um novo tipo de relação entre o conhecimento cientifico e outros tipos de conhecimentos, assegurando que a produção dos movimentos operários, feministas, LGBTQI+, negro, dos povos indígenas, cientistas e de todos os grupos que são marginalizados pelas elites dominantes, também passem a ser reconhecidos como válidos na busca de uma sociedade democrática e com mais justiça social.

Portanto, para essa agenda se materializar, é preciso potencializar uma ecologia de saberes revolucionários e transformadores nos espaços educativos, ampliando a leitura de mundo de todas e todos envolvidos nesse processo. Assim, defendemos a possibilidade de um diálogo intercultural entre os saberes 
de caráter progressista produzidos por todos esses grupos. 0 conceito de leitura do mundo de Freire (2011a; 2015a; 2015b; 2016) precisa dialogar com os saberes construídos na luta por emancipação do movimento negro educador (GOMES, 2017; NASCIMENTO, 2016), de pensadoras feministas (BLAY, 2017; HOOKS, 2019), ativistas de comunidades indígenas (GUAJAJARA, 2019; KRENAK, 2019) e intelectuais que demonstram as desigualdades socioeconômicas em suas produções, sejam elas acadêmicas (BAUMAN, 2010; SCHWARCZ, 2019; SOUZA, 2018) ou artísticas (BROWN, 2018; ROCK, 2018).

Além disso, a própria produção contra-hegemônica da Educação Física que vem problematizando os marcadores sociais de gênero (ALTMANN, 2015; GOELLNER, 2010), raça (COELHO et al, 2020; CORSINO; CONCEIÇÃO, 2016; NOBREGA, 2020); classe social (BONETTO, 2017; MALDONADO; BOCCHINI, 2015; NASCIMENTO; VIEIRA, 2014); e saúde (CARVALHO, 2005; FRAGA, 2013; PALMA, 2015), dentre outros marcadores sociais da diferença, precisa fazer um diálogo intercultural com os conceitos de leitura de mundo e a produção de saberes dos movimentos sociais.

O diálogo entre os conceitos de leitura de mundo e ecologia de saberes contra-hegemônicos, produzidos por Paulo Freire e Boaventura de Sousa Santos, encharcados de militância, ativismo e resistência, pode nos ajudar a pensar sobre o processo de conscientização e emancipação dos grupos oprimidos, já que a luta por direitos universais precisa continuar, mas levando em consideração a produção de saberes dos grupos que foram excluídos do debate pelo colonialismo, patriarcado e capitalismo.

É nesse encontro entre lutas macrossociais e resistências culturais, do cotidiano, que podemos pensar em uma leitura de mundo crítica a favor dos diversos grupos oprimidos no sistema político e econômico que vivemos. Talvez, o conceito de interculturalidade crítica defendido por Candau (2020), possa ampliar as reflexões sobre as relações de poder existentes na sociedade contemporânea entre diferentes grupos socioculturais e os movimentos de resistência por um mundo menos desigual economicamente.

Independente do tema que será problematizado nas aulas de educação física escolar, defendemos que os projetos de ensino organizados pelos docentes do componente curricular possam possibilitar a leitura de mundo, a conscientização e a politização dos estudantes sobre os saberes de resistência construídos historicamente sobre as práticas corporais e a relação dos jovens com o seu corpo, colocando em evidência conhecimentos marginalizados pela sociedade capitalista, principalmente aqueles relacionados com os marcadores sociais de gênero, classe, raça, geração, religião e saúde que atravessam a sociedade contemporânea, debatendo sempre sobre as relações de poder que constituem as identidades desses grupos no bojo da sociedade neoliberal que vivemos, na perspectiva de construir uma sociedade culturalmente plural e consciente das opressões ocasionadas por um sistema sociopolítico que necessita manter as desigualdades entre os seres humanos para continuar existindo.

Ao fazer a análise de um texto escrito por um dos estudantes dessa turma (Figura 3), percebemos que a experiência vivenciada com esses jovens possibilitou uma leitura de mundo crítica sobre os temas contra-hegemônicos debatidos nas aulas de educação física.

\section{Além das Quadras}

Muitas pessoas têm a visão errada sobre o que é a Educação Física e o que essa disciplina pode nos agregar e nos ensinar. Eu era uma dessas pessoas. Mas tive oportunidade de mudar e aprender quando passei no processo seletivo do Instituto Federal de São Paulo.

Tudo o que a humanidade construiu sobre os conhecimentos a respeito de práticas corporais - essa é a definição mais precisa e coerente sobre o que de fato é a Educação Fisica.

Mas a real, é que não há uma definição exata para descrever o que é. A Educação Física vai muito além de qualquer esporte e modalidade. Ela vai além das quadras.

Educação física é sobre saber entender que todos nós somos diferentes, mas mesmo assim não nos limitarmos à essas diferenças e correr atrás do que acreditamos, correr atrás dos nossos sonhos, e transformar o mundo em um lugar melhor de se viver Educação física é respeito, é cultura, é educação, é sociedade, e é iqualdade.

Educação física também é prática e linguagem corporal, onde abrange das mais diversas atividades e modalidades, como: brincadeiras, lutas, esportes, gestos corporais, ginásticas e danças. Ao decorrer do ano, tivemos o privilégio de estudar os diversos aspectos sociais, políticos, econômicos, históricos, biológicos e fisiológicos que cada uma dessas práticas corporais nos trazem.

Pude estudar as mais diversas desigualdades constantes que encontramos dentro do esporte, como a ausência de inclusão social; a presença do racismo enfrentado pelos atletas negros e o descaso com os atletas paralímpicos, fazendo com que recebam uma atenção desprezível das mídias e meios de comunicação.

Aprendi que a luta das mulheres dentro do esporte é constante, é um processo contínuo, e não foi da noite para o dia, e sim através de anos de luta e resistência. Mulheres são seres humanos, e jamais devem ser associadas com a fragilidade por simplesmente serem mulheres.

Aprendi que o esporte é saúde se for praticado da maneira correta, mas pode ser extremamente prejudicial se for praticado de maneira incorreta, causando lesões levando o corpo ao limite.

A Educação Física me ensinou que a raça humana acima de tudo, merece respeito. A empatia e amor ao próximo deve permanecer, dentro e fora do esporte. Enquanto houver diversidade, deve haver respeito.

Desse modo, finalizo o meu pequeno texto agradecendo ao professor, por cada ensinamento e aprendizado. Você me fez enxergar a Educação Física com outros olhos! Esse meu pequeno texto não tem nem um terço do que eu de fato aprendi ao decorrer do ano letivo de 2020 com a sua disciplina. Mas acima de tudo, aprendi que a Educação Física vai além das quadras.

Figura 3. Análise produzida por um aluno sobre a experiência vivenciada nas aulas de educação física. Fonte: Elaborado pelos estudantes

\section{CONCLUSÃO}

Ao narrar essa experiência, onde produzimos um projeto educativo para que docente e estudantes passassem a ler o mundo de forma crítica, a favor dos grupos oprimidos, sobre os saberes produzidos sobre as práticas corporais e o corpo, organizamos um processo de transgressão das fronteiras raciais, sexuais e de classe que perpassam os temas analisados (HOOKS, 2017), na tentativa de resistir ao discurso fatalista que aponta a aceitação de todas as desigualdades sociais impostas pelo sistema neoliberal, como se não houvesse outra forma de construir um mundo mais digno e justo.

Transgredir, para Arroyo (2013), significa combater uma concepção de políticas educacionais tecnicista, fria, regida pelos discursos da neutralidade, além de normatizada e regulada. Portanto, as transgressões pedagógicas coletivas produzidas pela comunidade escolar são realizadas com o intuito de driblar, nas brechas deixadas pelo sistema, essa visão reducionista das relações pedagógicas, criando um coletivo engajado politicamente.

Tentamos ainda, ao analisar o projeto educativo, fazer uma diálogo entre os conceitos de leitura de mundo e ecologia de saberes contra-hegemônicos, produzidos por Paulo Freire e Bo- 
aventura de Sousa Santos, na intencionalidade de defender que a função social das aulas de educação física escolar está relacionada com a produção de experiências que promovam a leitura crítica do mundo atrelada aos saberes produzidos sobre as danças, lutas, esportes, ginásticas, jogos, brincadeiras e a relação da sociedade com o corpo, pelos grupos que foram marginalizados no sistema capitalista, possibilitando que os estudantes leiam as lutas macro e microssociais dos movimentos sociais e da comunidade científica.

Nas últimas décadas, com a entrada e a permanência da Educação Física na área de Linguagens, se tornou possível efetivar projetos educativos em que os estudantes vivenciem os gestos das práticas corporais, analisem textos científicos e midiáticos, apreciem poesias, poemas e músicas, analisem filmes e documentários, criem charges e slams e produzam exposições virtuais que os possibilite ler o mundo criticamente sobre os conhecimentos históricos, sociais, políticos, econômicos, biológicos e fisiológicos das práticas corporais e da sua relação com o corpo, na perspectiva de compreender a luta histórica dos grupos oprimidos contra o sistema neoliberal e, por consequência, ter a possibilidade de se libertar dos discursos fatalistas, conservadores e de manutenção das desigualdades culturais, sociais e econômicas do sistema capitalista.

\section{REFERÊNCIAS}

ALTMANN, H. Educação física escolar: relações de gênero em jogo. São Paulo: Cortez, 2015.

ARROYO, M. Ofício de mestre: imagens e auto-imagens. 15. ed. Petrópolis: Vozes, 2013.

BAUMAN, Z. Capitalismo parasitário. Rio de Janeiro: Zahar, 2010.

BLAY, E. Al. Como as mulheres se construíram como agentes políticas e democráticas. In: BLAY, E. A.; AVELAR, L. 50 anos de feminismo: Argentina, Brasil e Chile: a construção das mulheres como atores políticos e democráticos. São Paulo: Edusp, 2017. p. 65-98.

BONETTO, P. X. R. “Craftando” um currículo cultural de educação física: uma experiência pedagógica com o jogo Minecraft. In: NEIRA, M. G. Educação física cultural: o currículo em ação. São Paulo: Labrador, 2017. p. 178-89.

BOSSLE, F. A história como tempo de possibilidades... In: SILVA, M. E. H.; MARTINS, R. M. Pressupostos freireanos na educação física escolar: ação e movimentos para a transformação. Curitiba: CRV, 2020. p. 17-22.

BROWN, M. Fórmula mágica da paz. Racionais MC'S. Sobrevivendo no inferno. São Paulo: Companhia das Letras, 2018. p. 121-32.

CANDAU, V. M. Diferenças, educação intercultural e decolonialidade: temas insurgentes. Revista Espaço do Currículo, João Pessoa, v. 13, n. Esp., p. 67886,2020

CARVALHO, Y. M. Entre o biológico e o social. Tensões no debate teórico acerca da saúde na educação física. Motrivivência, Florianópolis, v. 17, n. 24, p. 97-105, 2005.

COELHO, M. C.; ROCHA, L. O.; NUNES, L. de O.; MÜLLER, K. de A.; CONCEIÇÃO, V. J. dos S.; BOSSLE, F. . Negritude, pedagogia crítica e Educação Física Escolar: uma possibilidade de diálogo entre Aimé Césaire e Paulo Freire. In: BOROWSKI, E. B. V.; MEDEIROS, T. N.; BOSSLE, F. Por uma perspectiva crítica na educação física escolar: ensaiando possibilidades. Curitiba: CRV, 2020. p. 143-52.

CORSINO, L. N.; CONCEIÇÃO, W. L. Educação física escolar e relações étnicoraciais: subsídios para a implementação das Leis 10.639/03 e 11.645/08. Curitiba: CRV, 2016.

FREIRE, P. A importância do ato de ler: em três artigos que se completam. São Paulo: Cortez, 2011a.

FREIRE, P. Ação cultural para a libertação e outros escritos. 14. ed. Rio de Janeiro: Paz e Terra, 2011b.

FREIRE, P. Pedagogia do oprimido. 59. ed. Rio de Janeiro: Paz e Terra, 2015a. FREIRE, P. Pedagogia da autonomia: saberes necessários à prática educativa. 51. ed. Rio de Janeiro: Paz e Terra, 2015b.
FREIRE, P. Conscientização. São Paulo: Cortez, 2016.

FRAGA, A. B. A boa forma de João e o estilo de vida de Fernanda. In: LOURO, G. L.; FELIPE, J.; GOELLNER, S. V. Corpo, gênero e sexualidade: um debate contemporâneo na educação. 9. ed. Petrópolis: Vozes, 2013. p. 96-108.

GUAJAJARA, S. Educação indígena: esperança de cura para tempos de enfermidade. In: CÁSSIO, F. Educação contra a barbárie: por escolas democráticas e pela liberdade de ensinar. São Paulo: Boitempo, 2019. p. 171-4.

GOELLNER, S. V. A educação dos corpos, dos gêneros, e das sexualidades e o reconhecimento da diversidade. Cadernos de Formação RBCE, Campinas, v. 1, n. 2, p. 71-83, 2010.

HOOKS, B. Ensinando a transgredir: a educação como prática de liberdade. 2. ed. São Paulo: Martins Fontes, 2017.

HOOKS, B. Erguer a voz: pensar como feminista, pensar como negra. São Paulo: Elefante, 2019.

KRENAK, E. O indígena como usuário da lei: um estudo etnográfico de como o movimento da literatura indígena entende e usa a Lei no 11.645/2008. Caderno Cedes, Campinas, v. 39, n. 9, p. 321-56, 2019.

KUNZ, E. Transformação didático-pedagógica do esporte. 7. ed. Ijuí: Unijuí, 2006

MALDONADO, D. T. Professores e professoras de educação física progressistas do mundo, uni-vos. Curitiba: CRV, 2020.

MALDONADO, D. T.; BOCCHINI, D. Os jogos de tabuleiro na escola pública: as três dimensões do conteúdo e o desenvolvimento do pensamento crítico. Revista Brasileira de Educação Física Escolar, São Paulo, v. 1, n. 1, p. 44-53, 2015.

MALDONADO, D. T.; FARIAS, U. de S.; NOGUEIRA, V. A. Educação física e linguagem: por uma ecologia de saberes das práticas corporais na educação básica. In: MALDONADO, D. T.; FARIAS, U. de S.; NOGUEIRA, V. A. Linguagens na educação física escolar: diferentes formas de ler o mundo. Curitiba: CRV, 2021. p. 223-38

NASCIMENTO, A. O genocídio no negro brasileiro: processo de um racismo mascarado. São Paulo: Perspectivas, 2016.

NASCIMENTO, A. S.; VIEIRA, A. Tematizando o rap na escola: dias de luta ou dias de glória. In: NEIRA, M. G.; NUNES, M. L. F.; LIMA, M. E. Educação física e culturas: ensaios sobre a prática. Vol. 2. São Paulo: FEUSP, 2014. p. 261-82.

NEIRA, M. G. Educação física cultural: inspiração e prática pedagógica. Jundiaí: Paco, 2018.

NEIRA, M. G.; NUNES, M. L. F. Pedagogia da cultura corporal: críticas e alternativas. 2. ed. São Paulo: Phorte, 2008.

NOBREGA, C. C. dos S. Por uma educação física antirracista. Revista Brasileira de Educação Física e Esporte, São Paulo, v. 34, n. Esp., p. 51-61, 2020.

NOGUEIRA, V. A.; ARAÚJO, A. C. de; FARIAS, Ude S.; MALDONADO, D. T. Metodologias ativas e pensamento freiriano: a formação inicial da Educação Física em diálogo. In: SILVA, M. E. H.; MARTINS, R. M. Pressupostos freireanos na educação física escolar: ação e movimentos para a transformação. Curitiba: CRV, 2020. p. 111-24.

PALMA, A. A saúde sob o olhar dos estudos socioculturais. In: RECHIA, S (Org.). Dilemas e desafios da pós-graduação em educação física. Ijuí: Unijuí, 2015. p. 205-18.

ROCK, E. Mágico de Oz. Racionais MC'S. Sobrevivendo no inferno. São Paulo: Companhia das Letras, 2018. p. 113-8.

SCHWARCZ, L. M. Sobre o autoritarismo brasileiro. São Paulo: Companhia das Letras, 2019.

SOARES, C. L.; TAFFAREL, C. N. Z.; VARJAL, E.; CASTELLANI FILHO, L; ESCOBAR, M. O.; BRACHT, V. Metodologia do ensino de educação física. São Paulo: Cortez, 1992

SOUSA SANTOS, B. Um ocidente não-ocidentalista? A filosofia à venda, a douta ignorância e a aposta de Pascal. In: SOUZA SANTOS, B.; MENESES, M. P. Epistemologias do Sul. São Paulo: Cortez, 2010. p. 519-62.

SOUSA SANTOS, B. Na oficina do sociólogo artesão: aulas 2011-2016. São Paulo: Cortez, 2018.

SOUSA SANTOS, B. O fim do império cognitivo: a afirmação das epistemologias do Sul. Belo Horizonte: Autêntica, 2020.

SOUZA, J. Subcidadania brasileira: para entender o país além do jeitinho brasileiro. Rio de Janeiro: Leya, 2018. 
MALDONADO et al.

190 Lendo o mundo nas aulas de educação física no ensino médio: por uma ecologia de saberes contra-hegemônicos sobre as práticas corporais e o corpo

\section{CONFLITO DE INTERESSE}

Os autores do estudo declaram não haver conflito de interesses

\section{FINANCIAMENTO}

Este estudo não teve apoio financeiro.

\section{ORCID E E-MAIL DOS AUTORES}

Daniel Teixeira Maldonado (Autor Correspondente) ORCID: 0000-0002-0420-6490.

E-mail: danieltmaldonado@yahoo.com.br

Uirá de Siqueira Farias

ORCID: 0000-0001-7286-1000.

E-mail: uirasiqueira@yahoo.com.br

Valdilene Aline Nogueira

ORCID: 0000-0002-5271-1635.

E-mail: valdilenenogueira@yahoo.com.br 